\title{
Bio Polymerization as One of The Stimulation Cause of The Cancer Cell Multiplication
}

\author{
Zurab V Wardosanidze* \\ Institute of Cybernetics of the Georgian Technical University, LEPL Ilia Vekua Sukhumi Institute of Physics and Technology Georgia.
}

*Corresponding author: Zurab V Wardosanidze, Institute of Cybernetics of the Georgian Technical University LEPL Physicotechnical Institute named after Ilya Vekua Sukhumi Georgia.

To Cite This Article: Zurab V Wardosanidze, Bio Polymerization as One of The Stimulation Cause of The Cancer Cell Multiplication. Am J Biomed Sci \& Res. 2020 - 7(2). AJBSR.MS.ID.001125.

DOI: 10.34297 /AJBSR.2020.07.001125.

Received: 战 December 29, 2019; Published: 眥 February 03, 2020

\author{
Abstract \\ A possible mechanism of the occurrence of cancerous tumors in the body is proposed, according to which one of the reasons is the uncontrolled \\ bio polymerization processes under the influence of carcinogens and other factors.
}

\section{Introduction}

As it is known one of the general properties of the carcinogen materials and other influencers on the cancer evolution is their polymerizing properties. Therefore, we can assume that one of the factors stimulating the process of blocking of intercellular feedback is the bio polymerization process. Carcinogenic materials and other factors contribute to the blocking of intercellular metabolism and exchange of genetic information what complicates the genetic balance of biological processes [1]. As a result, the management of genetic processes by the central nervous system is weakened. After a certain concentration of carcinogenic substances and other factors acting on the cells, an uncontrolled polymerization process occurs, for example, of the membrane system between cells, and an uncontrolled process of cell reproduction begins, that is, cancer growth and the appearance of metastases. So, one of the important mechanisms of the cancer generation must be uncontrolled additional process of bio polymerization in the organism [2].

\section{Overview}

Let's list of the some carcinogens - substances of various chemical structures that can cause malignant tumors (cancer) and/ or benign neoplasms: Aflatoxins; Benzene; Benz (a) pyrenes; Vinyl chloride; Dioxins; Nitrates, nitrites; Cadmium and its compounds; Peroxides; Formaldehyde and so on. All of these materials are activators of polymerization processes.

Most chemical carcinogens are organic compounds, only a small number of inorganic substances have this ability [3]. According to
Miller, all carcinogens are, to one degree or another, electrophiles that easily interact with nucleophilic groups of nitrogenous bases of nucleic acids, in particular DNA, forming strong covalent bonds with them. The negative effects of carcinogens are manifested in the chemical modification of nucleic acids [4]. The consequences of such modifications are manifested in the impossibility of the proper course of DNA transcription and replication, which leads to the formation of the so-called DNA adducts associated with it. For example, in the replication of modified DNA, nucleotides that are associated with a carcinogen may not be read correctly by DNA polymerase, resulting in mutations. The accumulation of a large number of mutations in the genome leads to the transformation of normal cells into tumor cells, which is carcinogenesis.

Chemical carcinogens can be divided into two large groups:

a) Genotoxical

b) Non-genotoxical

Genotoxic carcinogens are chemical compounds in the interaction of which with DNA components can cause damage and mutations of the cell genome [5]. Mutations in turn can lead to the formation of tumor cells. Non-toxic carcinogens are chemicals that can cause damage to the genome only in high concentrations, with a very long and almost continuous exposure [6]. They cause uncontrolled cell proliferation, inhibit apoptosis, disrupt the interaction between cells (cell adhesion). Most non-genotoxic 
carcinogens are carcinogenesis promoters, such as organochlorine pesticides, hormones, fibrous materials, asbestos, especially dust.

According to the mode of action, genotoxic carcinogens can be divided into:

i. Substances containing alkyl and acetylating substancesN-nitrosyl alkylurea (NAM), epoxides (especially PAHs), ethyleneimine and its derivatives, chloroethylamine, etc.).

ii. indirect - low-activity substances that form covalently bound DNA adducts only after enzymatic activation, which occurs with the formation of highly active electrophilic metabolites that can interact with nucleophilic DNA groups (PAHs and their derivatives).

The most famous physical carcinogens are various types of ionizing radiation $(\alpha, \beta, \gamma$ radiation, $\mathrm{x}$-ray $\mathrm{x}$ radiation, neutron radiation, proton radiation, cluster radioactivity, ion fluxes, fission fragments), although they are also used to treat cancer. Ultraviolet is completely absorbed by the skin, and therefore can only cause melanoma. Whereas ionizing radiation, freely penetrating into the body, can cause radiogenic tumors of any tissues and organs of the body (quite often hematopoietic, due to high sensitivity). Microwave radiation.

The role of biological factors in carcinogenesis is not as great as that of chemical and physical factors, but in the etiology of some malignant tumors it is very significant [7]. So, up to $25 \%$ of cases of primary liver cancer in Asia and Africa are associated with hepatitis B virus infection. About 300,000 cases of cervical cancer per year and a significant proportion of cases of cancer of the penis are associated with sexually transmitted papillomaviruses (primarily HPV-16, HPV-18, HPV-33). Approximately $30-50 \%$ of cases of Hodgkin's lymphoma are associated with damage to the human body by the Epstein-Barr virus.

In the 1990s, convincing data were obtained on the dependence of most varieties of gastric cancer on infection with the bacterium Helicobacter pylori [8]. In any case, all processes of initiation and propagation of cancer cells can be associated with uncontrolled processes of bio polymerization.

\section{Conclusion}

According to the author, the role of polymerization processes in the body should be taken into account when studying and treating cancer [9]. From this point of view, one should look for ways to slow down or reverse the polymerization processes in the body. Based on the author's many years of experience, one of the most effective ways to prevent and treat cancer is the effects of passive radiation on the body in the optical range of $0.6-0.90 .6-0.9 \mu \mathrm{m}$ of the corresponding lasers or LED which increase the activity of weak intermolecular bonds.

\section{References}

1. Hatakeyama M, Higashi H (2005) Helicobacter pylori CagA: a new paradigm for bacterial carcinogenesis. Cancer Science Japanese Cancer Association 96(12): 835-843.

2. (2018) Agents Classified by the IARC Monographs. International Agency for Research on Cancer.

3. WHO (2018) IARC Monographs on the identifications of Carcinogenic Hazards to Humans 1(123): 4-17.

4. (1999) There is sufficient evidence in humans for the carcinogenicity of chromium [VI] compounds as encountered in the chromate production, chromate pigment production and chromium plating industries. International Agency for Research on Cancer.

5. Miller EC (1978) Some current perspectives on chemical carcinogenesis in human and experimental animals presidential address 38(6): 14791496.

6. Ilic Z, Crawford D, Vakharia D, Egner PA, Sell S (2010) GlutathioneS-transferase A3 knockout mice are sensitive to acute cytotoxic and genotoxic effects of aflatoxin B1. Toxicology and applied pharmacology 242(3): 241-246.

7. Kasper Dennis L (2004) Harrison's Principles of Internal Medicine, $\left(16^{\text {th }}\right.$ Edition). Mc Graw-Hill Professional, pp. 618.

8. Smith Martyn T (2010) Advances in understanding benzene health effects and susceptibility. Ann Rev Pub Health 31: 133-148.

9. Gandhi MK, Tellam JT, Khanna R (2004) Epstein-Barr virus-associated Hodgkin's lymphoma. British Journal of Hematology 125(3): 267-281. 